\title{
Photocoagulation of choroidal neovascular membranes with a diode laser
}

\author{
Michael W Ulbig, Dominic A McHugh, A M Peter Hamilton
}

\begin{abstract}
Nine eyes with parafoveal choroidal neovascular membranes due to age-related macular degeneration or angioid streaks were treated with a diode laser and were followed up to 40 weeks (mean 26 weeks). Angiographically proved closure of the membrane was achieved in seven eyes. Four lesions needed a second treatment for growth of subretinal neovascular tissue. Post-treatment visual acuity ranged from $6 / 9$ to $6 / 60$. Two eyes developed subfoveal membranes resulting in poor visual acuity. The morphology of the diode laser lesions differed from that of the argon green laser and was more similar to that of the krypton laser, producing a 'black hole' on the fluorescein positive print. In one particular eye fluorescein angiography revealed subfoveal choroidal non-perfusion next to the site of the diode lesion suggesting choroidal vascular closure.
\end{abstract}

(Brf Ophthalmol 1993; 77: 218-221)

The use of argon laser photocoagulation to treat subretinal neovascular membranes was first described in the early 1970s..$^{1-3}$ Subsequent trials have demonstrated that this form of treatment may reduce the incidence of severe visual loss. ${ }^{47}$

It was an early observation that macular irradiation with blue-green light (488 $\mathrm{nm}$ ) resulted in damage to the nerve fibre layer owing to absorption within the xanthophyll pigment. This has led to the deployment of longer wavelengths of laser radiation for the treatment of macular conditions - for example, argon green $(514 \mathrm{~nm})$ or krypton red $(647 \mathrm{~nm}) .^{8-11}$ Within this spectral wave band absorption within macular luteal pigment is very low.

Recent advances in semiconductor technology have resulted in the development of the diode laser. This has a number of advantages over current laser systems. These favourable

Table 1 Morphological and visual outcome in patients treated with diode laser photocoagulation

\begin{tabular}{|c|c|c|c|c|c|c|}
\hline \multirow[b]{2}{*}{$\begin{array}{l}\text { Casel } \\
\text { sex }\end{array}$} & \multirow[b]{2}{*}{$\begin{array}{l}\text { Age } \\
\text { (years) }\end{array}$} & \multicolumn{2}{|c|}{ Visual acuity } & \multirow[b]{2}{*}{ Final outcome } & \multirow{2}{*}{$\begin{array}{l}\text { Proximity } \\
\text { within/without } \\
200 \mu \mathrm{m} \text { FAZ }\end{array}$} & \multirow[b]{2}{*}{ Diagnosis } \\
\hline & & $\begin{array}{l}\text { Before } \\
\text { treatment }\end{array}$ & $\begin{array}{l}\text { After } \\
\text { treatment }\end{array}$ & & & \\
\hline $\begin{array}{l}1 \mathrm{~F} \\
2 \mathrm{~F} \\
3 \mathrm{~F} \\
4 \mathrm{~F} \\
5 \mathrm{M} \\
6 \mathrm{~F} \\
7 \mathrm{M} \\
8 \mathrm{M} \\
9 \mathrm{~F}\end{array}$ & $\begin{array}{l}48 \\
48 \\
53 \\
85 \\
82 \\
65 \\
75 \\
80 \\
77\end{array}$ & $\begin{array}{l}6 / 60 \\
6 / 12 \\
6 / 12 \\
6 / 9 \\
6 / 24 \\
6 / 9 \\
6 / 9 \\
6 / 9 \\
6 / 12\end{array}$ & $\begin{array}{l}6 / 24 \\
6 / 12 \\
6 / 60 \\
6 / 9 \\
6 / 36 \\
6 / 60 \\
6 / 60 \\
6 / 12 \\
6 / 36\end{array}$ & $\begin{array}{l}\text { Flat } \\
\text { Flat } \\
\text { Subfoveal } \\
\text { Flat } \\
\text { Flat } \\
\text { Subfoveal } \\
\text { Flat } \\
\text { Flat } \\
\text { Flat }\end{array}$ & $\begin{array}{l}\mathbf{X} \\
\mathbf{X} \\
\mathbf{X} \\
\mathbf{X}\end{array}$ & $\begin{array}{l}\text { PXE } \\
\text { PXE } \\
\text { SRNV } \\
\text { SRNV } \\
\text { SRNV } \\
\text { SRNV } \\
\text { SRNV } \\
\text { SRNV } \\
\text { SRNV }\end{array}$ \\
\hline
\end{tabular}

FAZ = foveolar avascular zone; Flat = no neovascular tissue visible in fluorescein angiography; Proximity = proximity of subretinal neovascular tissue to the foveola; PXE = pseudoxanthoma elasticum; Subfoveal = subfoveal neovascular membrane; SRNV=subretinal neovascular membrane. characteristics include compact size, a high electrical to optical conversion efficiency, the absence of requirement for ancillary cooling systems, and a long operating lifetime. ${ }^{12-16}$ The emission wavelength of currently available high power diode lasers is $810 \mathrm{~nm}$ (near infrared). In theory, this wavelength has superior transmission properties through cataract and haemorrhage compared with blue-green light. The absorption characteristics in the retina and choroid are similar to those of the krypton laser. ${ }^{17}$ In particular there is negligible absorption within macular luteal pigment. ${ }^{18}$ This study presents preliminary results of nine eyes with choroidal neovascular membranes which were treated with a diode laser.

\section{Patients and methods}

Nine consecutive patients, six women and three men, referred to the retinal diagnostic department at Moorfields eye hospital for photocoagulation of a subretinal neovascular membrane were recruited for treatment with the Keeler Microlase diode laser (Windsor, UK) emitting at $810 \mathrm{~nm}$. The laser was mounted on a Haag Streit 900 slit-lamp microscope (Bern, Switzerland). The patients ranged in age from 48 to 85 years. Six patients had age-related neovascular membranes in the eye to be treated, and advanced disciform lesions in the fellow eye (Table 1). Two of the three younger patients suffered from pseudoxanthoma elasticum associated with angioid streaks and a subretinal neovascular complex (Fig 1). One of them had good vision in the fellow eye, the other had lost vision owing to a subfoveal membrane. The remaining patient suffered from idiopathic neovascular maculopathy.

Treatment was performed between November 1990 and December 1991. Following mydriasis with tropicamide $1 \%$ (Mydracil) and topical anaesthesia with benoxinate $0.4 \%$ eye drops a Volk (USA) area centralis contact lens was applied. Treatment parameters were a spot size of $100 \mu \mathrm{m}$, exposure duration of 0.5 seconds, and powers between 0.7 and $1 \mathrm{~W}$. The end point was to produce a confluent greyish lesion extending to $100 \mu \mathrm{m}$ beyond the observed limits of the membrane. Five eyes had one treatment only. Four eyes were treated twice because of extension of the subretinal neovascular membrane contiguous to the former treatment scar. Colour fundus photographs and intravenous fluorescein angiography were obtained in all patients before treatment. The progress of the lesion was reviewed at 1 week, 1 month, and 3 months by fundus photographs, fluorescein angiography, and best corrected visual acuity. Visual acuity measurements were independently performed 
Figure 1(A) Subretinal neovascular tissue (arrow) due to angioid streaks associated with pseudoxanthoma elasticum.

Figure 1(B) The same eye as in Figure $1 A$ after treatment with a diode laser. The site of photocoagulation (arrow) now appears completely dark with well defined atrophy of the choriocapillary network.

Figure 1(C) Colour photograph of the same eye as in Figures $1 A$ and $1 B$ before treatment. by a trained nurse. Following treatment patients completed a questionnaire regarding symptoms of discomfort, pain, and excessive visual stimuli during therapy. The follow-up period ranged from 13 to 40 weeks (mean 26 weeks).

\section{Results}

Of the nine neovascular membranes treated, three were no longer detectable by fluorescein angiography 1 week after photocoagulation, and remained so for the follow-up period. Four others were not detectable at 1 week, but new
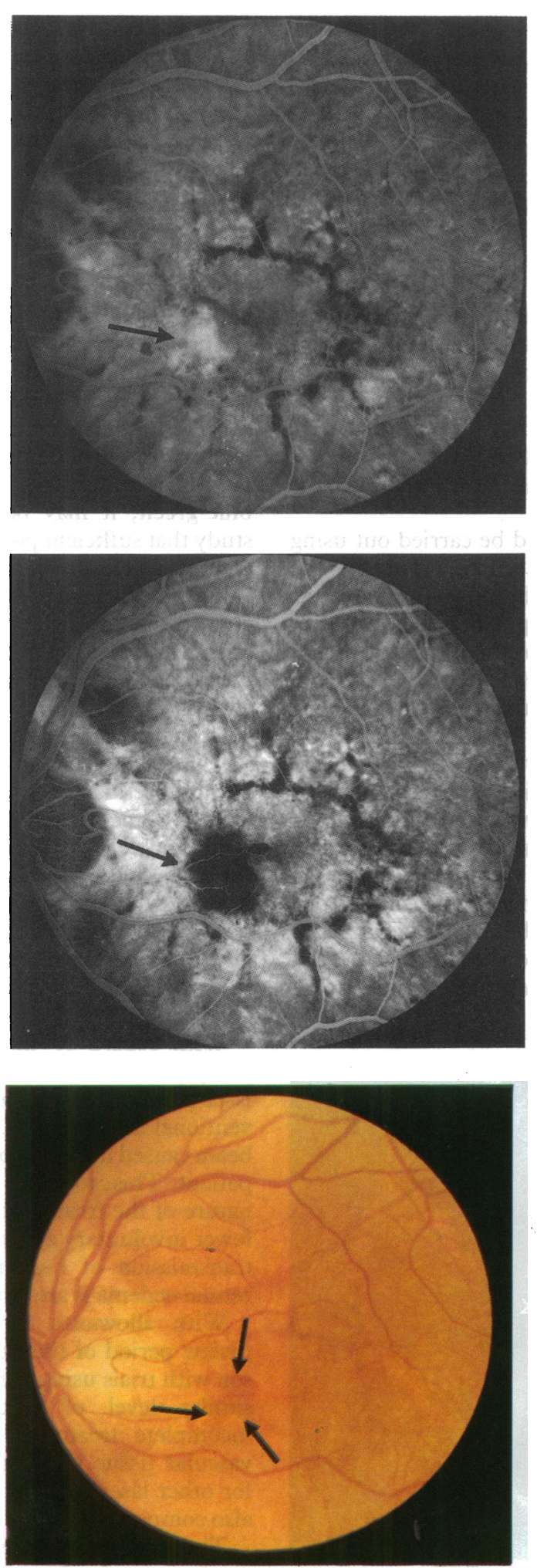

vessels again became visible 1 month after therapy. These four eyes underwent diode laser photocoagulation a second time. Subsequent fluorescein angiography has demonstrated no signs of neovascularisation. In two eyes the membrane initially was not detectable in the fluorescein angiogram, but at 3 months there was subfoveal extension, resulting in a visual acuity of $6 / 60$.

A change of two lines on the Snellen chart was taken to denote a significant decrease or increase in visual acuity. Accordingly, visual acuity had improved in one patient, was unchanged in four patients, and had deteriorated in four patients after a mean review period of 6 months (Table 1 ).

During therapy it was noted that no patient perceived any sensation of bright flashes. Mild or moderate discomfort was noticed during five treatments, but no patient complained about pain, and in no case was it necessary to abandon therapy, or to perform retrobulbar or peribulbar anaesthesia.

The high transmission of infrared light through blood ${ }^{18}$ was demonstrated by the ability to treat subretinal membranes through a thin layer of preretinal blood. The burns were partially visible at the edge of haemorrhagic

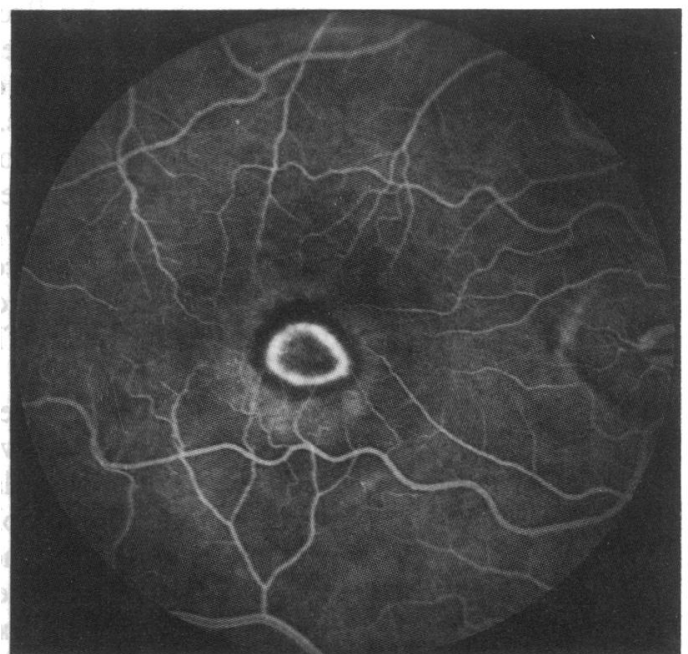

Figure 2(A) Choroidal neovascular membrane due to agerelated macular degeneration.

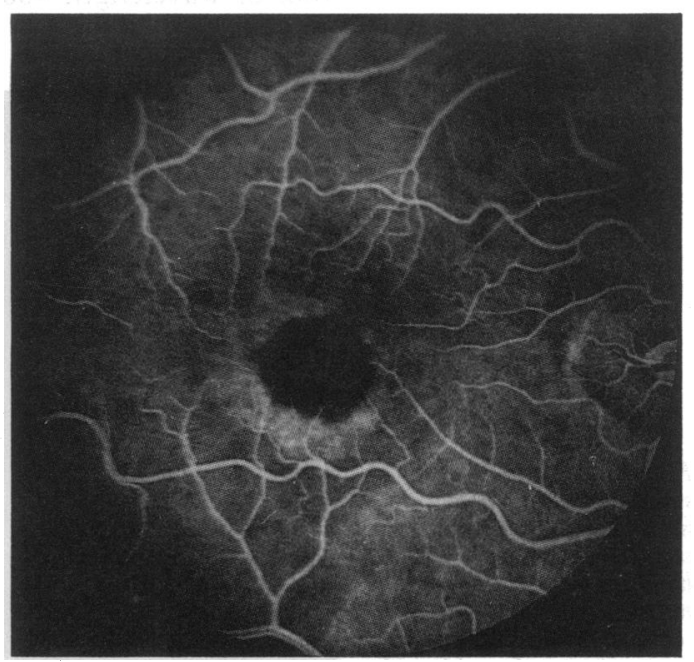

Figure 2(B) The same eye as in Figure $2 A$ after photocoagulation with the diode laser. The fluorescein angiogram reveals the typical appearance of a 'black hole'. 
areas, and photocoagulation scars were clearly seen following subsequent resorption of the blood. There was excellent penetration through retinal oedema and serous thickening. Acute diode laser lesions appeared deeper and more greyish when compared with argon lesions but coagulation of the underlying neovascular complex was intense. In all postoperative fluorescein angiograms the site of coagulation appeared completely dark with well defined atrophy of the choriocapillaris. The margins of the laser scars were not hyperfluorescent (Fig 2).

One particular patient who was treated twice for neovascular tissue contiguous to the former treatment scar showed subfoveal choroidal closure abjacent to the site of treatment (Fig 3). Only the very late phase of the angiogram revealed moderate choroidal filling in this particular area. It was assumed that a feeder vessel of a subfoveal choroidal lobe had been occluded by the recurrent diode laser coagulation. The visual acuity in this eye was not affected.

\section{Discussion}

A non-destructive mode of treatment for exudative macular degeneration or a preventive therapy are not available as yet, and the natural course of the disease has very poor visual outcome as shown by Bressler. ${ }^{19}$ Therefore, early detection of new vessel complexes and photocoagulation remain the only means to reduce the risk of major visual loss.

Photocoagulation should be carried out using the best available laser source. ${ }^{20}$ Despite the limited period of review, this pilot study suggests that diode laser photocoagulation is effective at inducing angiographic closure of choroidal neovascular membranes. The clinical appearance of the diode lesions was similar to that seen in relation to krypton red exposures, the burn being greyer and less white than argon induced lesions. ${ }^{10} 18$ Photocoagulation with near infrared has a number of biophysical advantages over treatment with laser radiation of shorter wavelengths. There is better transmission through media opacities - for example, nuclear sclerotic cataracts, and through blood. In relation to macular irradiation, while absorption of radiation of wavelength $488 \mathrm{~nm}$ (argon blue-green)

Figure 3 In this eye a subretinal neovascular membrane was treated twice with the diode laser. The black arrows show the treatment site. After the second treatment there was non-perfusion of a subfoveal choroidal lobe (white arrows). within luteal pigment is of the order of $70 \%$, it is less than $1 \%$ with krypton red or diode near infrared. ${ }^{21}$ Thus, while irradiation with the latter two wavelengths will give a burn which is confined to the outer retina and choroid, treatment with argon blue-green will result in a second locus of laser absorption within the inner retina, with damage to the nerve fibre layer and consequently central scotomatous field defects. ${ }^{9}$

The potential for non-therapeutic damage by blue-green light is not confined to the patient. Recent clinical studies ${ }^{22}$ have demonstrated the development of tritanopic defects in colour vision in surgeons using argon blue-green lasers. These defects are usually temporary, but in more frequent and longstanding laser users, the changes may become permanent. These changes are related to photochemical effects induced in blue sensitive cones by relatively high energy short wavelength light. They have not been observed in relation to green or red light. It may be expected therefore that diode near infrared irradiation in the macular region would demonstrate a similar level of safety.

Absorption of energy at $810 \mathrm{~nm}$ is very low within haemoglobin. It is clear therefore that closure of neovascular membranes must be achieved by absorption within melanin of the retinal pigment epithelium or within the choroidal melanocytes. Although absorption within melanin of diode near infrared radiation is only $15 \%$ of that seen in association with argon blue-green, it may be seen from the present study that sufficient power was available to effect anatomical closure of the membrane.

The mechanism of action of laser treatment of choroidal neovascular membranes is not known. One theory suggests direct destruction of the membrane, either by absorption of laser energy within blood, or by thermal transfer from adjacent melanin following laser absorption. ${ }^{23}$ An alternative hypothesis. suggests that laserinduced retinal pigment epithelial hyperplasia causes the membrane to be enveloped in pigment epithelial cells. ${ }^{24}$ The advantage of the latter theory is that one could employ energies which were less destructive to the outer retina. This would be of particular relevance in the treatment of subfoveal neovascular complexes in which the use of the krypton red laser is showing promise. ${ }^{25} 26$

With regard to the clinical results of this study, there were several advantages of diode laser photocoagulation over treatment with conventional laser systems. The near invisible laser beam caused no sensation of bright flashes for the patient. This, together with the almost painless nature of the treatment, resulted in there being fewer involuntary eye movements. The superior transmission of radiation through blood and retinal oedema is also an advantage.

With allowance for the relatively limited review period of this study, historical comparison with trials using the krypton laser suggests a similar level of efficacy. ${ }^{810} 11$ The rate of incomplete treatment, or recurrence of neovascular tissue was within the predicted limits for other laser sources, and visual outcome was also comparable. . $^{5-7}$

The most notable treatment induced incident 
was the closure of a choroidal lobe extending from the site of coagulation (Fig 3). This occurred after a second treatment of neovascular tissue contiguous to the treatment scar. Recently Bloom $^{27}$ described a case of choroidal nonperfusion after dye red $(630 \mathrm{~nm})$ photocoagulation for a peripapillary choroidal neovascular membrane. After initial deterioration visual acuity recovered well in his patient. Delayed choroidal vascular filling after krypton laser photocoagulation has been reported earlier by Johnson and Schatz. ${ }^{28}$ The deeper penetration of diode near infrared radiation into the choroid results in relatively greater absorption of energy within choroidal melanocytes. Thus, there is potentially a greater tendency for choroidal vascular closure to occur due to thermal transfer from the impact site. ${ }^{18}$ In treating choroidal neovascular membranes, this may be clinically advantageous, in that it may result in more effective closure of the lesion. In addition, by inducing local thrombosis of the choroidal vasculature, it may reduce the risk of incomplete treatment. In the eye in which choroidal vascular closure was assumed, there was no adverse effect on visual function as a result of this phenomenon, and thus far there has been no recurrence of the membrane.

In conclusion, the diode laser therapy appears as effective as other laser sources in coagulating subretinal neovascular tissue. It combines the favourable wavelength characteristics of the krypton red laser, in relation to its high transmission through blood, oedema, and macular xanthophyll, with the advantages of portable, less bulky, and less costly equipment. Clearly the long term effectiveness of diode laser photocoagulation in the treatment of subretinal neovascular membranes needs to be established when compared with argon green therapy. Clinical trials to examine this are currently in progress.

This work was supported by Deutsche Forschungsgemeinschaft ref: U1 109/1-1 and the Royal Society, European Science Exchange Programme ref: 623008.F621/DJHG/LM.

1 Gass JDM. Photocoagulation of macular lesions. Trans Am Acad Ophthalmol Otolaryngol 1971; 75: 581-608

2 Schatz H, Patz A. Exudative senile maculopathy: 1. Results of argon laser treatment. Arch Ophthalmol 1973; 90: 183-96.

3 Bird AC. Recent advances in the treatment of senile disciform macular degeneration by photocoagulation. $\mathrm{Br} \mathcal{F}$ Ophthalmol 1974; 58: 367-76.

4 Bird AC. Macular disciform response and laser treatment. Trans Ophthalmol Soc UK 1977; 97: 490-3.

5 Moorfields Macular Study Group. Treatment of senile disciform macular degeneration: a single-blind randomised trial by argon laser photocoagulation. Brf Ophthalmol 1983; 60: 745-52.

6 Macular Photocoagulation Study Group. Argon laser photocoagulation for idiopathic neovascularization. Results of randomized clinical trial. Arch Ophthalmol 1983; 101: 135861 .

7 Macular Photocoagulation Study Group. Argon laser photocoagulation for neovascular maculopathy. Three-year results from randomized clinical trials. Arch Ophthalmol 986; 104: 694-701.

8 Bird AC, Grey RHB. Photocoagulation of disciform macular lesions with krypton laser. Brf Ophthalmol 1979; 63: 66973.

9 Marshall J, Bird AC. A comparative histopathological study of argon and krypton laser irradiations of the human retina. BrF Ophthalmol 1979; 63: 657-68.

10 Oosterhuis JA. Argon and krypton laser photocoagulation of senile exudative macular degeneration. Doc Ophthalmol 1983; 55: $121-47$.

11 Yannuzzi LA. Krypton red laser photocoagulation for subretinal neovascularization. Retina 1982; 2: 15-28.

12 Brancato R, Patresi R, Leoni G, Trabucchi G, Giovannoni L Vanni U. Retinal photocoagulation with diode laser operating from a slitamp microscope. Lasers Light Ophthalmol ing from a s

13 McHugh JDA, Marshall J, Capon M, Rothery S, Raven A, Naylor RP. Transpupillary retinal photocoagulation in the eyes of rabbit and human using a diode laser. Lasers Light Ophthalmol 1988; 2: 125-43.

14 McHugh JDA, Marshall J, ffytche TJ, Hamilton AM, Raven $A$, Keeler CR. Initial clinical experience using a diode lase in the treatment of retinal vascular disease. Eye 1989; 3: 51627.

15 Puliafito CA, Deutsch TF, Boll J, To K. Semiconductor laser endophotocoagulation of the retina. Arch Ophthalmol 1987; 105: 424-7.

16 Brancato R, Patresi R, Leoni G, Trabucchi G, Vanni U. Histopathology of diode and argon laser lesions in rabbit retina. Invest Ophthalmol Vis Sci 1989; 30: 1504-10.

17 Gabel VP, Birngruber R, Hillenkamp F. Visible and near infra-red light absorption in pigment epithelium and choroid. Acta XXIII Concilium Ophthalmologicum (Kyoto) $1978 ; 1: 658-62$.

18 McHugh JDA, Marshall J, ffytche TJ, Hamilton AM, Raven A. Macular photocoagulation of human retina with a diode laser: a comparative histopathological study. Lasers Light Ophthalmol 1990; 3: 11-28.

19 Bressler SB, Bressler NM, Fine SL, Hillis A, Murphy RP, ,Olk $\mathrm{RJ}$, et al. Natural course of choroidal neovascular membranes within the foveal avascular zone in senile macular degeneration. Am f Ophthalmol 1982; 93: 157-63.

20 Mainster MA. Wavelength selection in macular photocoagulation: tissue optics, thermal effects, and laser systems. Coagulation: tissue optics, thermal

21 Nussbaum JJ, Pruett RC, Delori FC. Macular yellow pigment. The first 200 years. Retina $1981 ; 1: 296-310$

22 Berninger TA, Canning C, Strong N, Gunduz K, Arden GB Using argon laser blue light reduces ophthalmologists' colo contrast sensitivity. Arch Ophthalmol 1989; 107: 1453-8.

23 Guyer DR, Fine SL, Murphy RP, Green WR. Clinicopathologic correlation of krypton and argon laser photocoagulation in a patient with a subfoveal choroidal neovascula membrane. Retina 1986; 6: 157-63.

24 Miller H, Miller B, Ryan SJ. The role of the pigment epithelium in the involution of subretinal neovascularization. Invest Ophthalmol Vis Sci 1986; 27: 1644-52.

25 Coscas G, Soubrane G, Ramahefasolo C, Fardeau C. Perifovea laser treatment for subfoveal choroidal new vessels in agerelated macular degeneration. Results of a randomized clinical trial. Arch Ophthalmol 1991; 109: 1258-65.

26 Decker WL, Grabowski WM, Annesley WH. Krypton red laser photocoagulation of subretinal neovascular membranes located within the foveal avascular zone. Ophthalmolog 1984; 91: $1582-6$.

27 Bloom MS. Thermal papillitis after dye red photocoagulation of a peripapillary choroidal neovascular membrane. Retina $1990 ; 10: 261-4$

28 Johnson R, Schatz $H$. Delayed choroidal vascular filling after krypton laser photocoagulation. Am $\mathcal{F}$ Ophthalmol 1985; 99 . $154-8$. 